\title{
Water Supply, Sanitation and Hygiene Situation in Nepal: A Review
}

\author{
Chitra Bahadur Budhathoki, PhD*
}

\begin{abstract}
Federal Democratic Republic of Nepal is a landlocked country located in South Asia. Nepal has made its considerable efforts to improve the water supply and sanitation (WASH) situation in the country by formulating and enforcing a number of WASH policies, guidelines and acts for the last two decades. But WASH situation of Nepal has not been well documented so far. Aim of this article is to describe the situation of water supply, sanitation and hygiene (WASH) in Nepal by analysing secondary data and information obtained from published and unpublished literature. About 97 of the total population have access to basic sanitation facilities and 87 percent access to basic water supply facility. Sanitation coverage is 95 percent in six Provinces and below 90 percent in Province no. 2 of Nepal. The momentum of sanitation coverage was accelerated immediately after internalization and implementation of the Sanitation and Hygiene Master Plan in 201 I and Nepal reaches at close to the elimination of open defecation. The gap between rich and poor in accessing to and using toilet facility has been narrowing down due to the nationwide sanitation campaigns. But there is disparity in accessing and using piped water between rich and poor. Only 25 percent of water supply systems are well functioning and 68 percent can supply water to water taps throughout year. One-fourth of the existing toilet facility across the country are poorly constructed that needs to be upgraded. The government should make consolidated and integrated efforts to reduce existing inequity in the WASH sector and enhance the sustainability of water supply and sanitation services.
\end{abstract}

Key Words: Hygiene, sanitation, sustainability, WASH,

\section{Introduction}

Nepal is a small landlocked country in the South Asia, sandwiched between India and China with an estimated population of 28.4 million and an area of $147,|8|$ squares (CBS, 20I7). Geographically, Nepal can be divided into Terai plain, Hills and Mountain/Himalayan belt. New federal constitution promulgated in 2015 has divided the country into seven provinces with 77 districts and 753 municipalities and rural municipalities for political and administrative purposes. It is socio-culturally diverse country where 125 caste/ethnic groups coexist and I 23 dialects are spoken (Yadav, 20I4). Despite blessed with diverse natural resources, Nepal suffers from under development and chronic poverty due to lack of capacity to implement appropriate development efforts. Nepal is ranked 149 positions in the human development

\footnotetext{
* Professor, Central Department of Education, Tribhuvan University, Kathmandu, Nepal, Email: cbbudhathoki@gmail.com
} 
index prepared by the United Nation Development Programme (UNDP, 2018). About onequarter of the total population (25.16\%) still live below the poverty line, indicating the stagnation of economic growth and development in Nepal (CBS, 20II).

Nepal has made a notable progress in WASH Sector though a considerable proportion of the total population still lacks access to improved water supply and sanitation facilities. In 1990 before formulating National Sanitation policy 1994, 46 percent of the total population were using drinking water from the improved sources and only 6 percent had access to toilet facilities (NSASC, 2000). Census report shows that $85 \%$ of Nepalese households in $201 \mathrm{I}$ had access to improved water sources and 62 percent access to sanitation facility (CBS, 20I2). The involvement of users in the process of planning and implementation had significantly increased the coverage from $6 \%(1990)$ to $87.3 \%(2016)$ in sanitation and similarly $46 \%$ (1990) to $87 \%$ (2016) in water supply (MWSS, 2016).

The Government of Nepal has made its considerable efforts to improve the water supply and sanitation situation in the country by formulating and enforcing a number of WASH policies, guidelines and acts for the last two decades. In 1997, the government formulated a comprehensive 20 years' Water and Sanitation Strategies by setting a target of achieving $100 \%$ sanitation coverage in the country by $2017 \mathrm{AD}$. The government made its commitment to ensure the access of basic water supply and sanitation services to all people by the end of 2017 through the integrated National Rural Water Supply and Sanitation (RWSS) Policy and Strategy 2004 (HMG, 2004). Sanitation and Hygiene Master Plan (SHMP) was enforced by the government to gear up sanitation and hygiene programs ensuring access of all population to basic WASH facilities by the end 2017 (GoN, 20I I). After the implementation of the SHMP, the Governmental Organizations, and other WASH sector stakeholders strictly adhered to guiding principles in order to maintain uniformity and standard in the planning and implementation approach and to consolidate resources and unifying related stakeholders and actors in the WASH sectors of Nepal by forming coordination committees at different levels.

The Ministry of Water Supply and Sanitation has prepared a long-term sectorial development plan (SDP) by identifying priorities areas for future interventions and number of thematic approaches with an aim to achieving WASH sector goal by 2030. Aligned with the Sustainable Development Goals, SDP is guiding framework for planning, implementing, coordinating and monitoring all activities in the sector. The government has set target to provide basic WASH services to all population by 2020 and then improve services level (medium $50 \%$ and high $50 \%$ ) by the end 2030. In addition, Nepal has set specific targets in Sustainable Development Goal (SDG) 6 for the year 2030 that includes basic water supply coverage to 99 percent households, piped water supply and improved sanitation to 90 percent of households along with elimination of open defecation (NPC, 2018). Analysis of existing WASH situation reveals the actual gap that needs to be gradually fulfilled by the government to achieve SDGs at the end of 2030. In this context, this article analyses the progress and existing situation of WASH in Nepal. 


\section{Methods}

This article is based on review of published and unpublished literature related to WASH in Nepal. Published articles were searched through Google searched engine and HINARI. Most of the data and information used in this article were obtained from the published and unpublished documents of the Ministry of Water Supply and Sanitation, Department of Water Supply and Sewerage (DWSS) and Sector Efficiency Improvement Unit (SEIU), Office Kathmandu, Nepal. Some data of Nepal Demographic and Health Survey 2016, WHO, UNICEF and other relevant literature were also used to analyse the WASH situation of Nepal.

\section{Results}

\section{Water Supply and Sanitation Coverage in Nepal}

Data of DWSS (2018) shows that about 97 of the total population have access to basic sanitation facilities and 87 percent have access to basic water supply facility. By the end of 2018, 63 districts of Nepal achieved status of Open Free Defecation zones. Almost all people living in hill and mountain belts have access to basic sanitation facility. Coverage of sanitation facility in Terai is at 93 percent which is 3 percent below the national coverage.

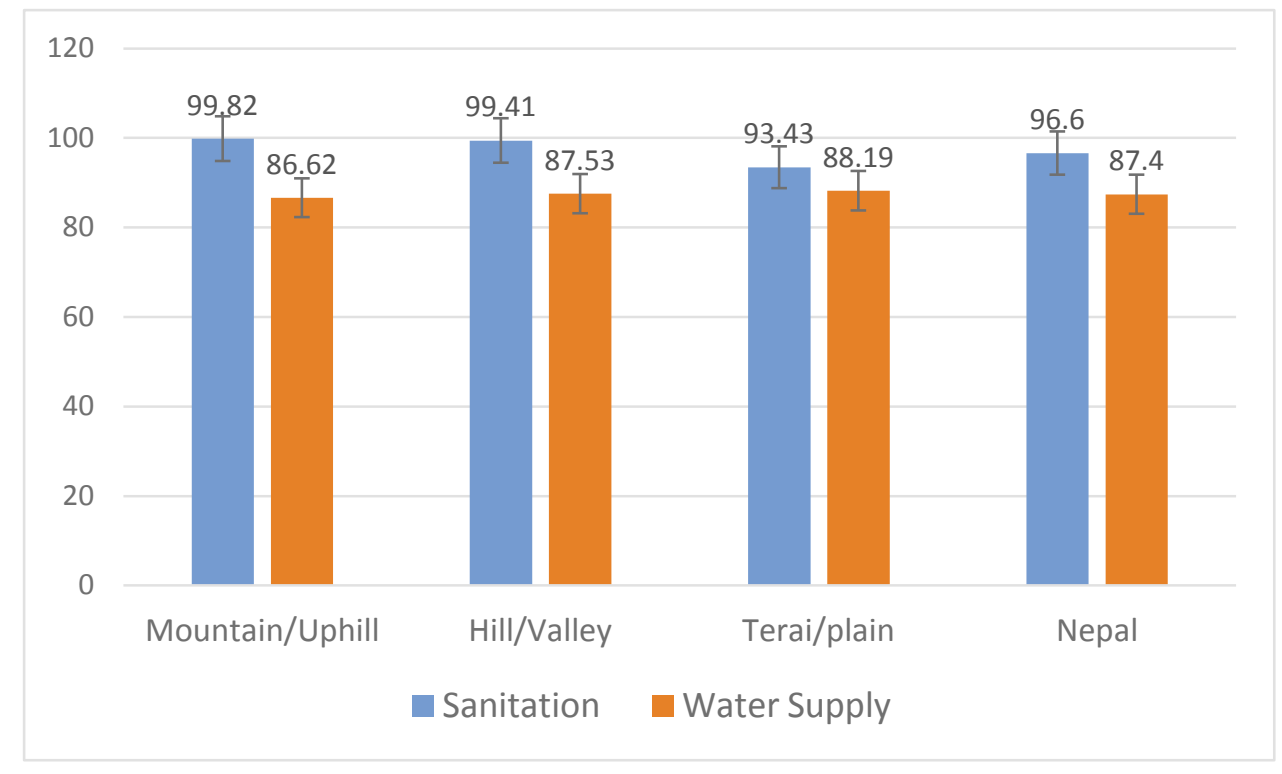

Figure I. Water supply and sanitation coverage by ecological belts

Source: DWSS 2018

Disparity in water supply facility can be observed among seven provinces of Nepal. The coverage of water supply facility is lowest $(70.45 \%)$ in the province 6 , which is mainly composed of remote and mountain districts. Ninety percent of the population in the province 3 with Kathmandu and Chitwan valleys have access to basic water supply service. Twenty four districts have water supply coverage more than 90 percent and only four districts have the coverage below 80 percent. Almost all households in three districts like Kailali, Dadeldhura and Manang have access to basic water supply facility. The existing coverage of water supply 
facility/services was estimated based on the data collected and recorded by the DWSS about completion of water supply facilities over the period. Actual coverage of the water supply facility might be below the existing coverage because all water supply facilities are not functional.

Table I

Water Supply and Sanitation Coverage in Seven Provinces of Nepal

\begin{tabular}{lll}
\hline Province & Water Supply & Sanitation \\
\hline Province One & 85.55 & 95.11 \\
Province Two & 87.86 & 88.19 \\
Province Three & 91.01 & 98.83 \\
Province Four & 89.68 & 100 \\
Province Five & 88.2 & 98.97 \\
Province Six & 70.45 & 100 \\
Province Seven & 87.39 & 96.62 \\
Nepal & 87.39 & 96.62 \\
\hline
\end{tabular}

Source: DWSS 2018

Coverage of basic sanitation facility is above 95 percent in all the provinces except in province 2. Province 4 and 6 have already achieved 100 percent coverage in basic sanitation facility. Fifty four districts of Nepal have been already declared as Open Defecation Free (ODF) zone. Three districts, Kathmandu, Sindhupalchowk and Sunsari have the 99 coverage of basic sanitation facility. Sanitation coverage below the 90 percent still exists in districts of province 2 where population are predominantly Madhisi and Muslim.

\section{Trend in Water Supply and Sanitation Coverage}

Before 1990 water supply and sanitation coverage was very low in Nepal. In the 1990 it was estimated that 36 percent of population had access to waters supply facility and only 6 percent of the total population were using toilet facility. People's access to basic sanitation facility increased from 36 percent in 1990 to 82 percent in 2000. Such a big achievement in water supply might be the government's concentrated efforts on water supply section neglecting sanitation sector in the decade of ninety. The coverage of basic water supply facility stagnated around 80 percent between 2000 and 2010. The government of Nepal could not make a big improvement in the population's access to toilet facility before the declaration million development goals.

Since 2000 the coverage of the sanitation facility increased gradually from 25 percentage and reached 62 percent in the 20II. The momentum of sanitation coverage was accelerated immediately after internalization and implementation of the SHM Plan in $201 \mathrm{l}$ by the government of Nepal. Within a period of six years, Nepal reaches at close to the elimination of open defecation and cent percent coverage of basic sanitation facility. Data indicate that 
Nepal will achieve the target of cent percent sanitation coverage and eliminate open defecation across the country within a few years.

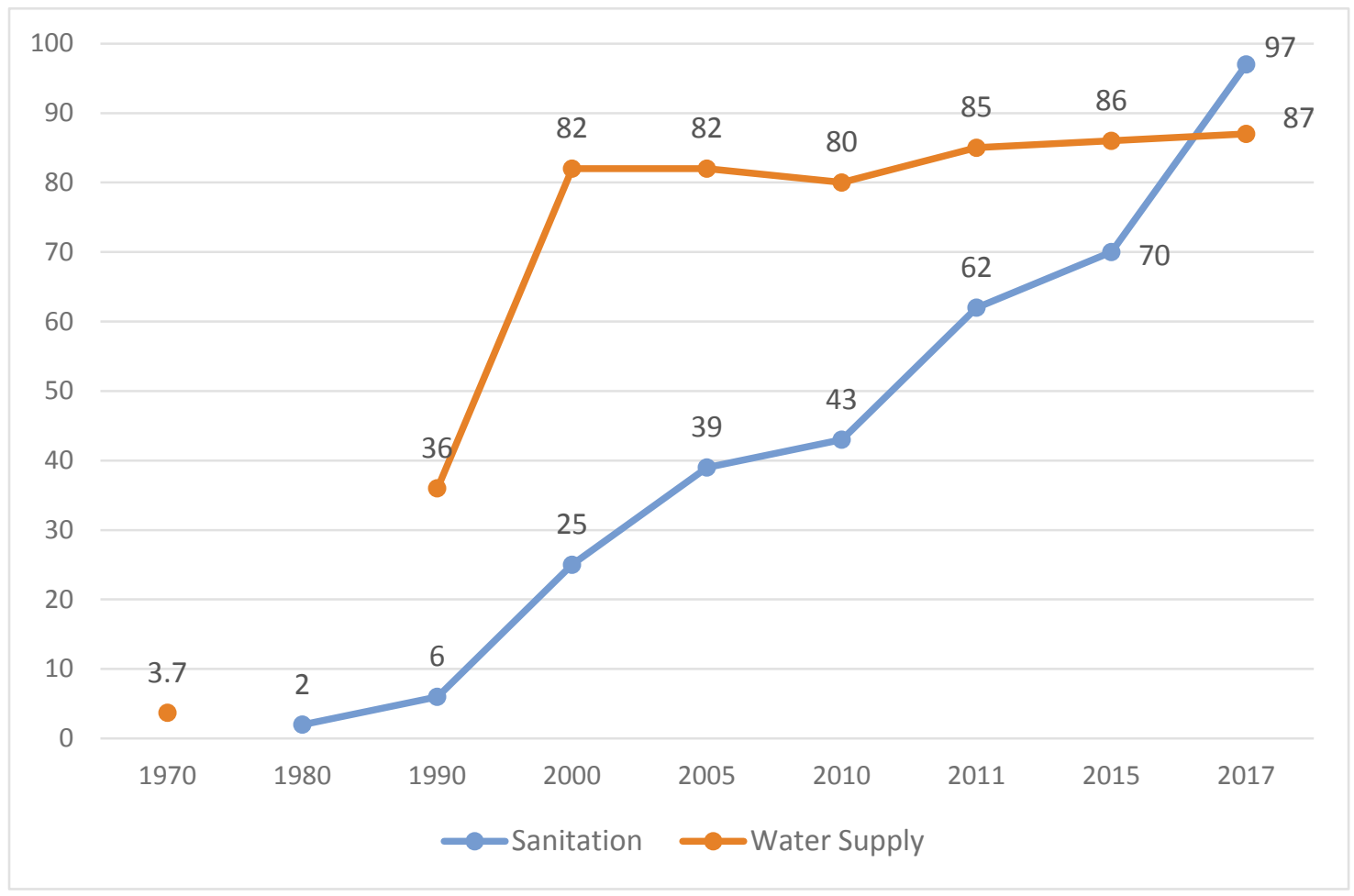

Figure 2. Trend of water supply and sanitation coverage in Nepal

Source: NSASC 2000, CBS 20II, NMIP 20I4, SEIU 2016, NMIP 2018

\section{Equity in WASH Sector of Nepal}

In rural areas most of piped water stands are found in the public places nearby houses. The piped water connection to houses or personal premises is less common in rural areas. Only some well-off households are able to have piped water connection to their houses in their own efforts. It is also evident from data that 35 percent of richest households have access to piped water in courtyard or home. But households from poorest quintiles are less likely to have piped water connection in their home. Available data indicates that there is a disparity in accessing and using piped water between rich and poor. 
Table 2

Status of water supply and sanitation by wealth quintile

\begin{tabular}{llllll}
\hline Water supply & Poorest & Second & Middle & Fourth & Richest \\
\hline Piped water on Premises & 10 & 14 & 16 & 17 & 35 \\
Other improved water & 69 & 82 & 84 & 83 & 64 \\
Unimproved water & 21 & 4 & 0 & 0 & 1 \\
Sanitation & & & & & \\
Open defecation & 69 & 53 & 42 & 28 & 1 \\
Other improved toilets & 11 & 14 & 14 & 8 & 34 \\
Shared Toilets & 4 & 11 & 12 & 22 & 0 \\
Improved flush toilets & 16 & 22 & 32 & 42 & 65
\end{tabular}

Source: WHO/UNICEF, 2015

Before initiating the open defecation free campaigns, access to toilet facility was limited to the rich and educated families, by and large in the urban areas. About 65 percent of households with richest quintiles are using improved flush toilet whereas only 16 percent of poorest quintiles have access to the improved flush toilet. Recent years, the gap between rich and poor in accessing to and using toilet facility has been narrowing down due to the nationwide sanitation campaigns.

Sanitation campaigns have also conducted hygiene promotion activities including establishment of hand washing facility with soap nearby toilet. According to Nepal Multiple Indicator Cluster Survey (CBS, 20I4), there was an identified place with water and soap or detergent or other cleansing agents for hand washing in 73 percent households. NDHS data shows that 81 percent of the households had a fixed place for hand washing, and 19 percent had a mobile hand washing place (MoH, New Era and ICF, 2017). Since 39 percent of households in the lowest wealth quintile did not have water or any cleansing agents for hand washing, poor households are less likely to wash hand with soap. Access to and use of improved sanitation facilities including the provision of hand washing place with soap are still determined by socioeconomic status of households.

\section{Functionality and Sustainability of WASH Facilities}

Functionality and sustainability of WASH facilities are influenced by several factors such as ownership of local people/users, management capacity of the user committee, skilled maintenance workers, operation and maintenance fund, availability of construction materials, tools and spare materials. Functioning status of the facilities by and large depend on the management capacity of the use committees and service providers as the water users and sanitation committees are responsible for managing water supply systems in rural and semiurban areas of Nepal. The management committees collect tariff and recruit human resources to operate and maintain the water supply systems. 
Table 3

Situation of functionality of water supply systems

\begin{tabular}{lll}
\hline SN & Functionality of systems and tap & Systems \\
\hline $\mathrm{I}$ & Functionality of water supply system & \\
& Well functioning & 25.4 \\
& Need minor repair & 36.1 \\
Need major repair & 9.2 \\
Need reconstruction & 8.6 \\
Need rehabilitation & 19.8 \\
non-functional & 0.9 \\
Providing water to all taps in the whole year & 68.2 \\
Condition of water tap stands & 78.4 \\
& Functioning, no need repair & 5.1 \\
Need minor repair & 16.5 \\
\hline
\end{tabular}

Source: NMIP 2014, Nationwide coverage and functional status of water supply and sanitation status in Nepal

Water supply systems constructed over the period in the country are not well functioning and are not capable to supply water to all taps throughout the year. NMIP (2014) reported that only 68 percent of water supply stems can supply water to all tap round the year. In terms of functionality, only 25 percent found functioning well and 36.1 percent can be promoted to the well functioning status through the minor repair. But 9 percent water supply stem is in the need of major repair, and 19 percent can function after the rehabilitation work, which is beyond the capacity of water user committees in the rural areas. Surprisingly, only 4.5 percent of the water supply systems have maintenance fund and 38 percent have kept maintenance tools on the sites (NMIP, 2014). Available data indicate that about 25-40 water supply systems are not in good condition to supply water to the community in reliable and sustainable way. Poorly functioning systems result in unreliable, insufficient and unsafe water supply, which has direct impact on the proper use and cleanliness of toilets and hand washing behaviour of people.

Table 4

Functional and sanitary status of toilets

\begin{tabular}{cl}
\hline Sanitary/functional & Percent \\
\hline Sanitary & 93.0 \\
Insanitary & 7.3 \\
Unused & 0.7 \\
Functionality & \\
Functional clean and sanitary & 78.0 \\
Insanitary and poorly maintained & 7.0 \\
No toilet or not used as toilet & 15.0 \\
\hline
\end{tabular}

Source: NMIP 2014, Progress Brief 2014-2016 Sustainable Sanitation \& Hygiene for All in Bhutan and Nepal 
The use of toilet has dramatically increased across the country due to the influence of nationwide sanitation campaigns. With the increased awareness of use of toilet, people have been habituated to use toilet. According to NMIP 2014, 93 percent of toilets in the country were sanitary and good condition and only 7 percent were insanitary. In term of functionality, 78 percent toilets were at good, clean, and sanitary condition. Only 7 percent toilets were not maintained properly by household members as toilet. There are some problems in the sustainability of sanitation facilities which can be overcome by upgrading simple pit latrine to improved pour/flush water seal latrine and ensuring easy access to water supply at household level.

\section{Discussion}

Water supply and sanitation has been on the priority areas of the government since international water supply and sanitation decade (198I-90). But sanitation which was considered as a component of water supply received low priority from the government by 2010 . As a result there was a huge gap in the water supply ( $82 \%$ and sanitation coverage $(25 \%)$ by the end of 2000. Despite governmental and non-governmental efforts including Rural Water Supply and Sanitation Improvement Projects, the coverage of water supply facility across the country got stagnated with only 5 percent incremental from 2000 to 2017 . About $87 \%$ of the total population in the country has access to basic water supply service. It may not be true reflection of water supply coverage in the country because this estimation was based on data collected by the DWSS regarding water supply scheme completion with beneficiary households and population without counting dysfunctional water supply system (DWSS, ND). On the other hand, NDHS data reveals that 95 percent households have access to an improved source of drinking water (MoH, New Era and ICF, 20I7). It was also estimated that only 45 percent household have access to piped water and about $40 \%$ depend on protect well and tube wells for drinking water, and 10 percent without access to basic water supply facility (DWSS, 20I5).

At present sanitation coverage of the country is estimated at 97 percent with minimal variation across ecological zones and provinces of the country. It was possible after the formulation and implementation of the National Sanitation and Hygiene Master Plan (SHMP) in 20II when the government intensified and scale up country cross the county through the formation of WASH Coordination Committees from top to bottom level, integration of non-governmental efforts with the government's targeted WASH programs, cross-sector linkage and application of Community Led/School Led Total Sanitation approach (DWSS, 2017). WASH Coordination Committees have promoted the community engagement, local leadership and collaborative efforts of various sectors and stakeholders in the sanitation campaign (Adhikari, Aryal and Shrestha, 2015). A wide acceptance of low cost technology for construction pour flush pit latrine by the local people also contributed to the rapid and equitable access to sanitation facility at the community level.

Population's access to improved sanitation facilities is significantly higher in urban areas (94\%) than in rural areas (67\%) (UNICEF and WHO, 20I5). But the gap between rural (6I\%) and 
urban (63\%) in the use of improved toilet facilities is being closed in the recent years (MoH, New Era and ICF, 2017) with the increased awareness of need of improved and sanitary toilet. There is inequity in access to and use of improved pour/flush toilet between well off and poor people. Households with poorest quintile are less likely to use the improved sanitation facility where as most of households from richest quintiles have access to improved pour/flash toilet. But rate of open defecation practice among people with poor quintile is higher than that of second and middle quintile people (MoH, New Era and ICF, 2017).

According to National Census data $201 \mathrm{I}$ there is only two percent gap in water supply coverage between urban (87\%) and rural areas (85\%) (CBS, 2012). But the proportion of households having piped water connection in their home or courtyard is very low $(20 \%)$ in rural areas (UNICEF and CBS, 20I4). In rural villages, drinking water is generally provided through public taps in each cluster of houses. Households with poor quintiles are less likely to have a piped water connection on their premise (10\%) because they cannot afford a connection to the piped water network as well as monthly water tariff. The wealth quintile data suggests unimproved water sources are more commonly used by the rural poor.

Sustainability of water supply facility is one of the major issues in the WASH sector of Nepal as most of drinking water supply schemes cannot function for the expected life span of 20 years (White et al. 2015). Only 25 percent of water supply systems are well functioning and 68 percent can supply water to water taps throughout year. According to the World Bank (2013), only $71 \%$ of water supply systems aged $5-15$ years were functional in terms of tap functioning, and 65 schemes were good in good condition (as cited in SEIU, 2016). Another study conducted by SNV Nepal (2013) reported that 78 percent tap stands were in good condition, 16.5 percent requires major repair and 5.1 percent was in the need of minor repair. It was also reported in WASH sector report 2016 that 30 to 40 percent of the schemes provided good services to the users. A considerable proportion of the schemes are dysfunctional and poorly maintained, which has direct impact on accessibility, quality and reliability of water supply. The poor functionality of water supply systems is mediated by several factors including negligence, inadequate application of water safety principles and lack of capacity of the water users' committee to carry out major and minor repairs. Weak institutional, financial and technical capacity of the users' committees in rural areas is the main obstacle for the sustainability of water supply systems (Bhandari and Grant, 2007; Chauhan 2013). There is also tendency of users as well as governing body depending on external resource and using available resources on the new project rather than maintaining and repairing the existing schemes.

Nepal is heading toward on the road to universal access to basic sanitation facilities and elimination of open defecation. Access to improved sanitation facilities is still below 65 percent in both urban and rural areas. However, there is inequity in access to improved sanitation facilities across poor and rich people. Most of poor people are likely to use unimproved toilet. Rapid expansion of basic sanitation facilities across the country indicates that the government will achieve the target, basic sanitation for all by the end of 2020. However, consolidated efforts need to be put on increasing access to improved sanitation facilities for all. Current 
estimation of water supply coverage cross the country may be quite below 87 percent as a considerable proportion of water supply systems are not functioning well. Inequitable distribution of and access to improved water supply facilities can be observed while analysing accessibility by wealth quintile.

\section{Conclusion}

In conclusion, it can be said that Nepal has made rapid progress in sanitation coverage, heading toward ensuring basic sanitation for all and eliminating open defecation from the country, by 2020. Implementation of SHM Plan 20I I across the country has been successful to reach the unreached, remote and poor communities, promote equity in access to basic sanitation services. A considerable proportion of the total population are still deprived of basic drinking water supply services, depending on unimproved and unreliable sources of water such as pond, unprotected well and stream. There is disparity in using improved source of water supply service between rich and poor people. Poor people are more likely to use the water from unimproved source of water. The government has to put concentrated and integrated efforts on water supply sectors in order to promote equitable water services and provide improved water supply facility for all people by the end of 2030. Majority of water supply systems are poorly functioning and cannot supply water to people throughout the year. The government should develop mechanisms to continuously review, refine and adapt its programming, approaches and technologies to make sure that the work is sustainable, innovative, relevant and effective. The government should make consolidated and integrated efforts to reduce existing inequity in the WASH sector and ensure access to the improved WASH facilities, enhance reliability, quality and sustainability of water supply services and achieve SDG in WASH sector by 2030 .

\section{Acknowledgement}

This paper has been prepared with the support from NORHED-Rupantaran Project Titled "Innovations in teaching and learning through contextualized approaches to increase the quality, relevance and sustainability of education in Nepal" which has been jointly implemented in Nepal by Tribhuvan University, Kathmandu University and Norwegian University of Life Sciences (NMBU). Author is grateful to the project coordinator and staffs for their valuable supports.

\section{References}

Adhikari, A. K, Aryal, B, \& Shrestha, N.L. (2015). Learning from the implementation of Sanitation and Hygiene Master Plan in Nepal, 38 th WEDC International Conference, Louborogh University, UK

Bhandari, B. \& M. Grant (2007). User Satisfaction and Sustainability of Drinking Water Schemes in Rural Communities of Nepal. Spring Vol.3: 12-20.

CBS (2012). National Population and Housing Census 2011. Central Bureau of Statistics, Government of Nepal, Kathmandu, Nepal. 
CBS (2018). Nepal in figure. Central Bureau of Statistics, Kathmandu.

Chauhan, K (2013). Environmental Sustainability of Water Supply Systems implemented at RWSSP-WN.

DWSS (2018). Sanitation status of Nepal: Factsheet. Government of Nepal, Ministry of Water Supply and Sanitation. Department of Water Supply and Sewarage (DWSS), Environmental Sanitation Section.

DWSS (2015). Progress review 2015. Kathmandu: Government of Nepal, Ministry of Water Supply and Sanitation, Department of Water Supply and Sewerage.

GoN (20II). Sanitation and hygiene master plan 20I I. Kathmandu, Nepal.

LGA (2017). Local Governance Act. Law Commission, Government of Nepal

Ministry of Water Supply and Sanitation (MWSS) (2016). Water, Sanitation and Hygiene (WASH) Sector status report 2016. Sector Efficiency Improvement Unit, Ministry of Water Supply and Sanitation, Kathmandu

MoH, New Era and ICF (2017). Nepal Demographic and Health Survey 2016. Ministry of Health, New Era and ICF, Kathmandu.

National Management Information Project (NMIP) (2014), Nationwide coverage and functionality status of water supply and sanitation in Nepal, Department of Water Supply and Sewerage, Kathmandu.

Nepal Central Bureau of Statistics (CBS) (20II). Nepal Living Standards Survey 2010-20I I, NLSS Third. Kathmandu: Government of Nepal.

Nepal Ministry of Federal Affairs and Local Development (MoFALD) (199I). Local Self Governance Act (1991). Kathmandu: Government of Nepal.

Nepal Ministry of Physical Planning and Works (MoPPW) (2004). Rural Water Supply and Sanitation National Policy \& Rural Water Supply and Sanitation National Strategy 2004. Kathmandu: Government of Nepal.

NPC (2018). Nepal Sustainable Development Goals Status and Road Map (20162030), National Planning Commission Government of Nepal, Kathmandu, Nepal.

NSASC (2000). Nepal state of sanitation report 1999/2000. National Sanitation Action Steering Committee, Kathmandu.

Sector Efficiency Improvement Unit (SEIU) (2016). Water, sanitation and hygiene (WASH), Sector Status Report, Ministry of Water Supply and Sanitation, Kathmandu.

Sector Efficiency Improvement Unit (SEIU) (ND). Nepal water supply, sanitation and hygiene sector development plan (2016-2030), Ministry of Water Supply and Sanitation, Kathmandu.

SNV, Progress Brief 2014-2016 Sustainable Sanitation \& Hygiene for All in Bhutan and Nepal.

UNDP (2018). Human Development Report 2017, United Nations Development Programme, New York 
WHO and UNICEF (20I5). Progress on Sanitation and Drinking-water, 2015 Update. World Health Organization and UNICEF: Geneva.

White, P., Badu, I.R., \& Shrestha, P. (2015). Achieving sustainable water supply through better institutions, design innovations and Water Safety Plans - an experience from Nepal. Journal of Water, Sanitation and Hygiene for Development, 5(4). 625-63I

WHO and UNICEF (2017). Progress on Drinking Water Sanitation and Hygiene 2017 Update and SDG Baselines, World Health Organization (WHO) and the United Nations Children's Fund (UNICEF) Joint Monitoring Programme, Geneva. 